\title{
De Nova Orleans ao Brasil: o jazz no Mundo Atlântico
}

From New Orleans to Brazil: jazz in the Atlantic World

Petrônio Domingues ${ }^{*}$

\section{Resumo}

O jazz teria nascido na cidade de Nova Orleans, nos Estados Unidos, durante o primeiro quartel do século XX. Em curto intervalo de tempo, esse gênero de origem afro-diaspórica fez um sucesso assombroso, converteu-se em símbolo musical da modernidade e viajou pelas redes de conexões de bens simbólicos pela Europa e pelas Américas, desembarcando no Brasil. O artigo tem a intenção de traçar algumas notas acerca da ascensão do jazz nos Estados Unidos e, a partir daí, mapear e discutir quando e como essa nova sonoridade se estabeleceu em terra brasilis, conferindo atenção especial ao eixo Rio de Janeiro-São Paulo, cidades-palco de uma efervescente cena de jazz-bands nos anos 1920. Palavras-chave: jazz; música; negro.

\section{Abstract}

Jazz was born in New Orleans, United States, during the first quarter of the 20th century. This Afro-diasporic origin genre became a haunting success and a musical symbol of modernity. It traveled through the networks connecting symbolic goods throughout Europe and the Americas until reaching Brazil. The first aim of the present article is to draw some notes on jazz rise in the United States; therefore, the goal is to map and discuss when and how this new sonority settled in terra brasilis. It also intends to focus on Rio de Janeiro and São Paulo, for these cities hosted the lively jazz-bands scene in the 1920s. Keywords: jazz; music; blackness.

Em 1922, os Oito Batutas, sob a direção de Pixinguinha e incluindo Donga e outros protagonistas da música popular do Rio de Janeiro, excursionaram por Paris durante quase seis meses, de meados de fevereiro ao final de julho. Nessa temporada, o grupo - na França chamado de Les Batutas - apresentou-se no Shéhérazade, Chez Duque, La Réserve de Saint Cloud, entre outros cabarés e casas noturnas. A princípio, o repertório do grupo era formado

\footnotetext{
* Universidade Federal de Sergipe (UFS), São Cristóvão, SE, Brasil. petroniojosedomingues@gmail.com $<$ https://orcid.org/0000-0002-0116-5064>
} 
somente por ritmos brasileiros - chorinhos, maxixes, sambas e outras músicas "indígenas" -, até para preservar a originalidade em uma cidade ocupada por músicos do mundo inteiro, principalmente músicos negros dos Estados Unidos e do Caribe. Lá os integrantes dos Oito Batutas teriam entrado em contato com o jazz, estabelecendo convivência com os músicos de quatro jazz-bands, com os quais chegaram a tocar juntos. O intercâmbio com a música norte-americana teria influenciado fortemente os Oito Batutas. Basta dizer que Pixinguinha voltou de Paris tocando saxofone e, sob o patrocínio de Arnaldo Guinle, o grupo encomendou uma bateria igualzinha à usada pelas bandas da terra de Tio Sam. Na "bagagem", portanto, os Oito Batutas trouxeram novos instrumentos - saxofone, clarinete e trompete -, além do foxtrote, charleston, shimmy e outras novidades sonoras e dançantes ligadas à experiência jazzística. Três dias depois do retorno de Paris, os Oito Batutas realizaram um show na sede do aristocrático Jóquei Clube Brasileiro, no Rio de Janeiro, ocasião na qual o grupo teria exibido, pela primeira vez, o "gênero jazz-band", o que começou a virar mania. Teria sido, assim, graças aos Oito Batutas, com destaque para Pixinguinha, que o jazz aportou no Brasil (Bastos, 2005; Cabral, 2007; Martins, 2014; Neto, 2017).

Será que essa narrativa, que vem sendo contada e recontada ao longo das décadas, tem respaldo nas fontes históricas? O intuito deste artigo é justamente investigar o emaranhado processo de chegada do jazz ao Brasil. Quais foram os fatos, cenários e personagens que despontaram no primeiro momento do gênero aqui? Antes, porém, de responder a essas questões, cabe indagar: o que é jazz? Quando e onde ele nasceu e se expandiu em ritmo vertiginoso, tornando-se um fenômeno da nascente indústria cultural e símbolo palpitante da modernidade? Em síntese, qual a trajetória do jazz, para ter predominado na paisagem artístico-cultural do Mundo Atlântico nas primeiras décadas do século XX? Vamos aos fatos, cientes de que este artigo é apenas o primeiro passo no sentido de captar, reconstituir e compreender o processo de produção, circulação e recepção da cultura jazzística no Brasil.

\section{O JAZZ ENTRA EM CENA}

Não existe uma certidão de nascimento do jazz. É seguro afirmar que esse estilo musical derivou do encontro de duas tradições culturais: a africana ocidental e a europeia (Stearns, 1956). Das contribuições dos africanos que vieram trabalhar nas plantations das Américas, o ritmo seria a principal delas. A cadência, própria da música sincopada, também conhecida como swing ou 
balanceio rítmico, é característica do jazz e dos estilos sonoros que reportam à matriz africana. Já os traços principais da música europeia encontrados no jazz são a harmonia, os instrumentos e a técnica. Em geral, uma jazz-band do início do século XX era formada por bateria, violão, baixo, piano e metais (sax, trompete e trombone), além de outros instrumentos de sopro como clarinetas e flautas. A técnica usada para tocá-los, assim como as noções de teoria musical (como partitura, tempos, compassos, intervalos, enfim, tudo ligado à técnica instrumental) são contribuições do Velho Continente.

Atribui-se a Nova Orleans o berço do jazz (Gioia, 1997). A cidade, capital do estado da Louisiana, fundada em 1718, sediava um porto que impulsionou o tráfico negreiro e um pujante fluxo de navios, mercadorias, pessoas e artefatos culturais de todas as partes do Atlântico (de Martinica, Haiti, França, Espanha, Holanda e Inglaterra), um melting pot que mesclava soberanamente todas essas influências para delas extrair a música (Billard, 2001; Ulanov, 1957).

Foi do amálgama de estilos sonoros, do ragtime e do blues, acrescido da antiga tradição de brass bands (bandas musicais que seguiam em carroças e animavam de casamentos a funerais), que surgiu o jazz. Não há consenso de quando isso ocorreu exatamente. Marshall Stearns acredita que, antes de se usar o nome jazz, o gênero já existia sem nome próprio ou se confundia com outras formas musicais (Stearns, 1956). Podemos, então, adotar a primeira década do século XX como a de nascimento e/ou consolidação do jazz; e o período de 1900 a 1920 como o de sua consagração como gênero específico nos Estados Unidos, sem falar de sua divulgação em outros países.

Fato é que o jazz rapidamente se expandiu e conquistou adeptos para além de Nova Orleans. Em 1915, a banda do trombonista Tom Brown foi apresentada num clube de Chicago como a Brown's Dixieland Jass Band, de Nova Orleans. Parece ter sido a primeira vez que a palavra jass, assim grafada com dois "s", era veiculada em público. Há controvérsia quanto à origem da palavra. Alguns dizem que ela remete ao perfume de jasmim das prostitutas de Storyville - um bairro boêmio de Nova Orleans, onde se localizava a zona de meretrício. Outros, que é uma adaptação do verbo francês jaser (tagarelar). Na versão mais difundida, a palavra jazz seria uma gíria para o ato sexual, o que lhe conferia, no início, uma conotação pornográfica. Por isso havia certo denodo ao usá-la. ${ }^{1}$

A princípio, o jazz ganhou força como um som eminentemente negro, associado à cultura da boemia de Nova Orleans. Não tardou, entretanto, para o jazz sair do "gueto", cair no gosto de pessoas brancas e da "boa sociedade", tornando-se um fenômeno da emergente indústria cultural.

Logo após o final da Primeira Guerra, os Estados Unidos experimentaram 
um crescimento espetacular, com altos índices de desenvolvimento científico e tecnológico, produção industrial, exportações e consumismo no mercado interno, o que lhes permitiu que alcançassem liderança da economia mundial e definissem novos estilos de vida e padrões culturais, catalisados na expressão American Way of Life (Hobsbawm, 1995). Enquanto a terra de prosperidade e oportunidades desfrutava de sua "época de ouro", sua juventude dançava ao ritmo das bandas de jazz e um grupo de pessoas negras protagonizava em Nova York o Harlem Renaissance, um movimento de afirmação cultural e identitária (Helbling, 1999). A nação vivia uma busca desenfreada pelo prazer e pelo experimentalismo - e a genialidade do cantor e instrumentista Louis Armstrong talvez fosse a face mais visível desse furor contagiante. Entre 1925 e 1928, ele e seus grupos Hot Five e Hot Seven fizeram o estilo deixar de ser apenas uma música para se tornar o estado de espírito de uma era, "a era do jazz", como tão bem definiu Scott Fitzgerald a atmosfera cultural dos anos 1920: de entusiasmo coletivo, renovação de hábitos e costumes, ascensão de novos gêneros e inventos tecnológicos relacionados ao consumo, fruição e bem-estar (Fitzgerald, 1965; Wilson, 1987). Da abjeção inicial para o frisson das novas gerações, eis o triunfo da "música popular da era da máquina". Nas palavras de Antonio Ferro, a "América vibra[va] toda no ritmo da jazz-band" (Ferro, 1922, p. 64).

O jazz foi a primeira manifestação musical dos negros nos Estados Unidos a romper a barreira de cor e alcançar sucesso descomunal em todas as classes sociais, tendendo a se converter em um símbolo cultural da nação (Borge, 2018). Num contexto histórico em que grassavam as políticas de segregação baseadas na cor da pele, esse fato é importante para entendermos o sentido inovador - de afirmação racial e revalorização do negro - do jazz (Grossman, 1997). Foi assim que a música passou a circular em todos os cantos e recantos do país, atravessou o Atlântico e caiu na graça do público europeu.

No Velho Continente, o epicentro do jazz foi Paris, a cidade francesa reconhecida como a "capital cultural do mundo", que reunia grandes artistas vanguardistas - Pablo Picasso, Henri Matisse, André Derain, Blaise Cendrars, André Breton, Guillaume Appolinaire, Paul Éluard, Jean Cocteau, entre outros (Gay, 2009). Como as linguagens estéticas da modernidade - na pintura, na escultura, na fotografia, na literatura, na música, na dança, no teatro, nas artes populares e noutros artefatos culturais de herança africana e afro diaspórica - ali estavam em voga, houve um ambiente bastante receptivo ao jazz. Pintores, escultores, escritores, dramaturgos e poetas da "Cidade Luz" ficaram fascinados com uma sonoridade que rompia as barreiras do formalismo clássico, do puro e simples aperfeiçoamento técnico, para valorizar a liberdade de formas 
(improviso), o swing (síncope) e a infusão do emocional (que toca o coração) à arte (Blake, 1999). Fato é que o jazz - com toda sua mística transgressora de primitivismo, espontaneidade, exotismo e sensualidade - foi adotado como a expressão musical mais autêntica da modernidade.

Também residiam em Paris "muitos homens de cor", que "trabalhavam nos bares, cafés e restaurantes, desenvolvendo nas orquestras e jazz-bands um labor musical verdadeiramente hercúleo" (O Clarim d'Alvorada, p. 3). Foram esses e outros espaços de sociabilidade, cultura e lazer que abriram as portas e acolheram diversos artistas e jazzmen afro-americanos, tornando-se locais privilegiados de referência, diálogos e trocas culturais transnacionais. $\mathrm{O}$ ícone dessa geração foi Josephine Baker, uma negra cuja história de superação foi contada por sua biógrafa: de uma anônima dançarina de cabaré, proibida de se apresentar em teatros de brancos, malsinada e repudiada nos Estados Unidos, seu país de origem, ela atravessou o oceano para se tornar, do dia para noite, a "Cleópatra do Jazz", a "Rainha de Paris" (Rose, 1990).

Outra cidade que se tornou eixo irradiador do jazz e ponto de interseção e troca de experiências entre os músicos do gênero foi Buenos Aires. Micol Seigel afirma que, "assim como Paris, e muito mais que outras capitais sul-americanas, Buenos Aires promoveu encontros interamericanos”, nos quais "itinerantes brasileiros, norte-americanos e outros estrangeiros puderam estabelecer contato com visões e sons uns dos outros, tenham eles ou não viajado pelos Estados Unidos ou Brasil” (Seigel, 2009, p. 103). O jazz entrou em cena no plano internacional da afro diáspora (Gilroy, 2001; Hall, 2003). Viajou nos fluxos de bens simbólicos e redes de conexões culturais pela Europa e pelas Américas (Borge, 2018). Circulou pelo Mundo Atlântico, desembarcando no Brasil.

\section{NO RASTRO DO JAZZ EM TERRA BRASILIS}

A presença da matriz fundante do jazz no Brasil é antiga. Remonta ao início do século XX, porém foi a partir da década de 1920 que a nova onda musical emplacou de maneira avassaladora. "A coisa pegou de tal maneira", afirma Sérgio Cabral, "que a resposta a um convite para um baile ou chá dançante passou a ser sempre a mesma: É com jazz?” (Cabral, 2007, p. 114). Apesar desse ingente impacto na vida cultural da nação, os primeiros momentos do jazz aqui permanecem envoltos em uma cortina de fumaça, com os poucos autores de livros que trataram do assunto não chegando a consenso.

Ary Vasconcellos, um estudioso reconhecido da música popular, argu- 
menta que por volta de 1912 chegaram ao Brasil os primeiros ragtimes e aponta o ano de 1919 como marco da influência musical norte-americana, que se instalou em nossos costumes. Teriam aparecido ali os primeiros foxtrotes. $\mathrm{O}$ "saxofone começou a substituir a flauta, a pulsação rítmica passou a ser dada pela guitarra e bateria” (Vasconcellos, 1977, p. 27).

Almirante (1963), outro autor bastante referenciado acerca da história da música popular brasileira, assinala que, entre 1923 e 1926, o “movimento melódico" sofreu transformação intensa no Brasil. Vários ritmos norte-americanos - shimmy, charleston, blues, black-bottom - predominaram em períodos distintos. Surgiu a "jazz-band, orquestras exóticas e instrumentos estrambóticos" - trombones extensos, trompetes com varas de quase dois metros, banjos metálicos, "grotescos" violinofones ou violinos de campana e, finalmente, baterias com bombos-de-pedais, sem falar dos mais "esquisitos apetrechos tais como panelas, frigideiras (de cozinha) e latas, apitos, buzinas, sirenas etc." (Almirante, 1963, p. 30-31).

Já Jorge Guinle, um bon vivant carioca apaixonado por jazz, escreveu um livro sobre essa forma musical e, a partir de suas memórias, assevera que: "Por volta de 1920 começou a se tocar foxtrote no Brasil e foi o conjunto de Harry Kosarin, procedente de Buenos Aires, provavelmente o primeiro que introduziu essa novidade musical" (Guinle, 1953, p. 89). Teria sido também esta a primeira vez que se usou entre nós a bateria norte-americana "com pedal no surdo mestre, instrumento até então desconhecido dos nossos músicos, que usavam nessa época somente a caixa (snare drum) sem tripé, amarrada por uma cordinha a uma cadeira" (Guinle, 1953, p. 89).

Quando pesquisamos os cronistas, memorialistas, jornais e revistas do início do século XX, percebemos que antes de se falar em jazz, outros gêneros como o ragtime, one-step, two-step, fox trote e, anteriormente, o cake-walk eram objeto de anúncios, notas, reportagens, análises e controvérsias diversas. Vicente de Paula Araújo, um respeitado cronista paulista, registrou em livro qual era a última novidade da cena artístico-cultural de São Paulo em 1903:

Quem lia jornal naquele tempo sabia muito bem que uma dança saída das senzalas dos escravos americanos fazia furor nos salões mais aristocráticos dos Estados Unidos, da Inglaterra e da França. Chamava-se cake-walk e foi anunciada pela primeira vez em São Paulo para ser dançada no palco do Polytheama-Concerto, por duas troupes, Brandford e Cherton (Araújo, 1981, p. 96)

Jorge Americano - outro prestigiado cronista, que nasceu em São Paulo em 1891 - é mais lacônico no livro que escreveu sobre o cotidiano da sua 
cidade natal, entre os anos de 1895 e 1915: "Durante um tempo se dançou o cake-walk" (Americano, 2004, p. 218).

Em maio de 1903, a revista $O$ Rio $N u$ informou que "tem feito real sucesso no Cassino o novo grupo chegado no Atlantique": os Prospers, que apresentariam "Nelly Auestin, cantora e bailarina anglo-americana e o célebre cake walk" (O Rio-Nú, 1903, p. 3). Um mês depois, o diário o Paiz anunciava que, no Parque Fluminense, haveria um "grande concerto popular", com a orquestra sob a direção do conhecido maestro Costa Júnior. No "cinematógrafo, o célebre Cake walk infernal" (O Paiz, 1903, p. 4). A Revista da Semana estampou, em julho de 1903, imagens de artistas que executavam no Cassino Nacional o cake-walk, a "popular dança americana" (Revista da Semana, 1903, n. 164, p. 158) A revista $O$ Malho, em sua edição de julho de 1904, alardeou: o Rio de Janeiro não "fala de outra coisa - a companhia inglesa", que encenou uma opereta em dois atos do repertório. Ali haveria de tudo, inclusive dançarinas que "remexiam pinotes complicados, chahut miudinho, schottisch, polka militar, lanceiros e cake walk" (O Malho, 1904, n. 95, p. 5).

Naquele contexto, um articulista do jornal O Fluminense se perguntava: "o que é que quer dizer cake walk? Eis a pergunta que ouço de todos os cantos. Todos querem saber donde surgiu tal dança e o que significa esse estrangeiro nome" (O Fluminense, 1904, p. 2). Adolfo Morales de Los Rios - um arquiteto, urbanista e historiador argentino que se radicou no Brasil em 1890 - procurou satisfazer tão grande curiosidade em importante estudo sobre o Rio de Janeiro da Primeira República: "para perturbar as elegantes e rítmicas danças, não faltava quem deixasse de apreciar a dança norte-americana denominada cake-walk, aqui aparecida em 1904" (Rios Filho, 1966, p.79). Tratava-se de uma "verdadeira loucura coreográfica", levada a efeito por "grupos de homens e mulheres", em movimentos de "avanços e recuos, pontapés no espaço, trejeitos os mais inverossímeis, agachamentos que mais pareciam quedas, sapateios de toda espécie, braços ao alto erguidos, ou abaixados, pendidos" (Rios Filho, 1966, p. 79). Tudo isso, segundo Morales de Los Rios, "ao som de música cheia de estridências; trepidante, voluptuosa, maluca” (Rios Filho, 1966, p. 79). Talvez seja por isso que João do Rio, em crônica publicada na Gazeta de Notícias, em 1906, faz alusão a rapazes "espirituosos", que empurram o "corpo como quem vai dançar o cake-walk” (Abreu, 2017). ${ }^{2}$ O Paiz de junho de 1906 publicou a partitura de um "verdadeiro cake-walk: Giorgia Marcha” (O Paiz, 1906, p. 7).

Assim, já pelo início do século XX, diversas são as referências ao cake-walk, sendo até possível que, pelo final do século anterior, a dança tenha feito sua estreia no Brasil, pelas companhias de circo ou teatro. Porém, foram os 
aparelhos de reprodução musical gravada em cilindros ou discos, como o gramofone, que talvez mais contribuíram para a difusão do cake-walk. Ouvir as gravações que chegavam dos Estados Unidos - por exemplo, o Cake-walk do malandro, de 1903, em cilindro; em disco o "Cake-walk colored coquette, de 1908, pela Victor; o two-step em 1913 com Caraboo, e o one-step e o fox-trot entre 1913 e 1914 em discos Phoenix e Gaúcho" (Tinhorão, 1998, p. 250) tornou-se cada vez mais comum.

Em depoimento sobre a sua vida, o compositor Francisco Mignone afirma que, na década de 1910, quando iniciou sua carreira profissional, tocando nos cinemas, festas e bailes na capital paulista, teve em seu repertório diversas músicas desses gêneros, que chegavam por meio de músicas populares para piano, em edições de luxo, que vinham da América do Norte (Ikeda, 1988).

Desde ao menos 1907 há notícias sobre o ragtime na imprensa brasileira (O Paiz, 1907), mas foi em meados da década seguinte que esse ritmo dançante, lançado no "music hall" e logo difundido "desde as contorções dos negros da América do Norte" (Revista da Semana, 1914, p. 6), ganhou popularidade nos salões e clubes dos mais diversos setores da sociedade. Entre 1915 e 1916, os jornais da capital da República anunciavam o lançamento de composições musicais, como os ragtimes "Pitutinho" e "Venturoso" (A Noite, 1916, p. 5; 1917 , p. 5) a venda, por parte das casas editoras de música, de ragtimes (Correio da Manhã, 1916, p. 7; 1916, p. 3); o concerto de bandas de músicas com "ragtime dance" (Gazeta de Notícias, 1916, p. 5), as festas nas sociedades recreativas à base de um "delicioso ragtime" (O Paiz, 1916, p. 7; 1916, p. 5; Jornal do Brasil, 1917, p. 8), sem falar de professores que ofereciam aulas de "danças da moda (ragtime e outras)" (A Noite, 1915, p. 5).

No entanto, as evidências mais insofismáveis da presença do espírito jazzístico no Brasil são do ano de 1917. A bateria "tipo norte-americana” foi a novidade que mais chamou a atenção do nosso meio musical, por isso a revista Fon-Fon, no início de dezembro de 1917, destacou a contratação de um baterista para a orquestra do Teatro Fênix, no Rio de Janeiro:

Pois bem esta glória cabe aos Estados Unidos de onde veio agora para a orquestra do Teatro Fênix um músico trepidante que, além de batucar em onze instrumentos diversos, ainda por cima sopra nuns canudos estridentes e remexe-se durante todo o espetáculo, numa espécie de gigue circunscrita ao lugar que ele ocupa no meio dos seus colegas. (Fon-Fon, 1917, n. 48, p. 29)

O periódico, na mesma reportagem, estampou a foto das "endiabradas Americans Girls", que "tem revolucionado nossa jeunesse dorée", protagonizando um 
espetáculo no Teatro Fênix de "sucesso sem precedente no Rio", com números de "originalíssimas danças e cantos do seu país" (Fon-Fon, 1917, n. 48, p. 29).

Pelo que se pode depreender de outras edições de Fon-Fon, as "Americans Girls" estavam na crista da onda e seu espetáculo ainda contava com o baterista dos "onze instrumentos" (Fon-Fon, 1917, n. 49, p. 22; 1917, n. 50, p. 24).

A presença da bateria - um dos elementos que mais caracterizavam as jazz-bands - pressupunha a existência de um grupo instrumental, acompanhando as canções e danças modernas típicas dos Estados Unidos, encenadas, naquele instante, pelas Americans Girls. Esse mesmo grupo entrou em cartaz no Teatro Apollo, de São Paulo, na última quinzena de dezembro de 1917, apresentando-se com o nome de American RagTime Revue, reportou o jornal Estado de São Paulo (O Estado de São Paulo, 19/12/1917, p. 12). Convém ressaltar que, nesse $\mathrm{ano}^{3}$, o termo jazz ainda era de uso incerto mesmo nos Estados Unidos, e alguns especialistas identificam o ragtime como uma forma primeira de jazz (Ikeda, 1984, p. 117). ${ }^{4}$

Em março de 1919, o Alfinete, um jornal da chamada "imprensa negra", publicou um artigo cujo autor fazia alusão a "certos modernismos": "Existe em São Paulo grande número de sociedades de homens de cor, umas dramáticas recreativas, outras recreativas dançantes" (O Alfinete, 1919, p. 1-2), mas, segundo o articulista, poucas dedicadas à beneficência social, por isso ele conclamava: "Precisamos mostrar que não são somente os ones-steps, ragtime e picadinhos que sabemos cultivar, também sentimos amor e boa vontade para as cousas instrutivas" (O Alfinete, 1919, p. 1-2). Percebe-se que "certos modernismos", apesar de alvo de críticas, eram cultivados pelas "sociedades de homens de cor”. Em novembro de 1919, outro jornal congênere, A Liberdade, perguntava-se por que as sociedades dos "homens de cor" adotaram o ragtime. "Essa mesma pergunta poderia fazer aos diretores de todas as sociedades, certo, porém, que a resposta seria: - adotamos porque é a dança da moda" (A Liberdade, 1919, p. 2).

Naquele mesmo mês, A Liberdade noticiou que um baile em favor do jornal foi realizado na capital paulista, regado a música e com direito a um concurso de dança: "O concurso, que era para RagTime e Valsa de Resistência, realizou-se com todas as regras exigidas, parecendo não terem os inscritos queixa alguma a dar da comissão julgadora”. A matéria do periódico, que repercutia o baile, elencou ainda os critérios de avaliação dos dançarinos: "1) sahida [ou não] ao compasso da música; 2) posição do corpo; 3) elegância”. Para participar desse concurso, "se inscreveram Manoel Pestana, Luiz Henrique, Virgílio Vasconcellos, que se retirou antes do começo do concurso, João 
Batista Prates, Roberto Cardoso, Francisco Bruno, João Pereira da Rocha, João Braga, Norberto Rocha e Leonel Penna”. "No Ragtime (damas tirar cavalheiros) coube o prêmio 'A Liberdade' ao sr. João Rocha, e o prêmio 'Kosmos' a D. Mercedes de Moura” (A Liberdade. 1919, p. 1).

Partindo dessas fontes, observamos como o ragtime, considerado o pai do jazz, fazia-se presente no meio negro antes da década de 1920. Mais do que isso: a notícia do baile do concurso sugere que seus frequentadores, especialmente os inscritos no certame, tinham familiaridade com o ragtime, dos passos da dança até as regras do estilo. Isso indica que parcela dos afro-brasileiros estava em sintonia com as músicas modernas de caráter dançante, protagonizadas pelos seus "irmãos de cor" do outro lado da linha do Equador.

Em 6 de julho de 1919, o diário A Noite, do Rio de Janeiro, noticiou que o "Cine-Palais, no intuito de proporcionar variedades aos seus frequentadores, substituirá a partir de amanhã a orquestra nacional dos ' 8 batutas' pela 'The American Jazz Band"' (A Noite, 1919, p. 5). Com a temporada da The American Jazz Band na capital da República, abriram-se novas perspectivas para a música jazzística no Brasil. Vê-se aí a citação direta do vocábulo jazz no nome do conjunto.

A partir de agosto de 1919, o vocábulo jazz apareceu no jornal O Estado de São Paulo, grafado no espaço reservado à propaganda de espetáculos em cartaz na capital paulista: "excelente Ragtime Band de Harry Kosarin, com soberbo repertório de novidades Newyorkinas" (O Estado de São Paulo, 28/08/1919, p. 13). Essa mesma banda se identificava nos anúncios publicitários com outros nomes, tais como: American Rag Jazzing Band, Harry Kosarin's Jazz Band, Harry Kosarin Jazz Band e Harry Kosarin with his Jass Band. Em muitos desses anúncios apareciam as fotos de Kosarin e também de Louis Poland, que tocava banjo (O Estado de São Paulo, 16/01/1920, p. 13).

Harry Kosarin era baterista, pianista, chefe de orquestra, além de uma espécie de representante de editoras norte-americanas no Brasil, onde se radicou. Provavelmente era ele o baterista dos "onze instrumentos" da temporada no Teatro Fênix (RJ), em 1917, que subia ao palco acompanhando as American Girls e, a posteriori, foi a São Paulo adotando o nome American RagTime Revue. Com a temporada de Harry Kosarin com a sua jazz-band em terras bandeirantes, entre agosto de 1919 e fevereiro de 1920, fica fora de qualquer dúvida a presença da música jazzística “entre nós” (Ikeda, 1988, p. 84).

Não há, portanto, respaldo nas fontes históricas consultadas para a versão de que Pixinguinha teria entrado em contato com a música jazzística somente em Paris, por ocasião da turnê dos Oito Batutas, em 1922. Os Batutas decerto 
conheceram a The American Jazz Band, conjunto musical que os substituiu como atração do Cine-Palais, no Rio de Janeiro, em agosto de 1919. Ainda nesse ano, os Batutas estiveram em São Paulo justamente quando o grande acontecimento artístico-musical da cidade era a banda de Kosarin. É bem plausível que Pixinguinha tivesse conhecido Kosarin ou ao menos ouvido nele falar naquele contexto, sobretudo se levarmos em conta que se tratava de São Paulo de 1919 e não da atual megalópole. É possível até que o líder dos Oito Batutas tivesse estabelecido conexões com esse tipo de música ainda antes, na temporada das American Girls, no Rio de Janeiro (Ikeda, 1984).

Em 1921, a Munson Steamship Line inaugurou uma rota marítima entre Rio de Janeiro e Nova York. A bordo da primeira viagem dessa linha estava a Orquestra Sul-Americana-Brasileira, chefiada pelo prestigiado Romeu Silva, músico com o qual Pixinguinha mantinha amizade. Quando o navio retornou ao Rio de Janeiro, "coincidentemente" Silva mudou o nome de sua orquestra para Jazz-Band Sul-Americana, passou a tocar sax tenor e adaptou instrumentos e arranjos típicos de "música de pancadaria" (Seigel, 2009, p. 102). Esse fato, per se, já coloca em xeque a versão de que somente em 1922 Pixinguinha teria estabelecido contato com um mundo musical para ele "absolutamente inédito", conforme sustenta o jornalista Lira Neto em livro recente. ${ }^{6} \mathrm{O}$ que provavelmente ocorreu foi que, apenas em Paris, Pixinguinha tenha se convencido da nova rendez-vous da música instrumental que eram as jazz-bands, pois, nesse caso, quem estava ditando a tendência era a "capital cultural do mundo". Se as jazz-bands norte-americanas estavam fazendo sucesso na "Cidade Luz", isso para um brasileiro seria a prova cabal de que a "coisa era boa, bela e moderna" (Ikeda, 1984, p. 121).

Seja como for, a nova sensação - as danças e músicas modernas, agrupadas sob a genérica denominação de jazz - emplacou de forma meteórica no Brasil durante a década de 1920. Em pesquisa sobre a história cultural de São Paulo desse período, Nicolau Sevcenko mostra como, entre os segmentos sociais mais elitizados, proliferaram os bailes e ambientes de dança relacionados ao lazer, assim como os clubes, as sociedades dançantes e as casas dedicadas aos music-hall. Várias lojas da "fina flor" da cidade, para atrair a clientela feminina, tiveram que transformar o seu tradicional "chá das cinco" em um, a partir de então superlotado, "chá dançante". O tipo de música que se dançava nesses lugares era "variado na classificação, mas uniforme no acento rítmico" (Sevcenko, 1992, p. 90).

Por outro viés, o memorialista Jacob Penteado comenta que, em 1921, nos bairros de imigrantes do Brás e do Belenzinho, eram numerosas as "socieda- 
des-recreativas" cujos salões de bailes aderiram às novas tendências rítmicas e sonoras. Nas palavras de Penteado, as "danças de outrora - 'xotes', polcas, mazurcas, quadrilha, lanceiros, 'pas-de-quatre"” - cederam lugar a outras, "mais modernas, tais como tango, rancheira, foxtrot, one-step, two-step, ragtime (influência americana, que já começava a invadir-nos), charleston, habanera e o velho e muito caboclo maxixe" (Penteado, 1963, p. 47-48).

Em obra de 1925, outro memorialista, Sylvio Floreal, conta que, quando o sol esmaecia no "poente numa agonia langorosa e prolongada", a Rua Direita, no centro de São Paulo, regurgitava da patuleia: "Entro na Confeitaria Fasoli. $\mathrm{O}$ vasto salão, sempre cheio de homens e mulheres, delira entusiasticamente, animado pela música que toca sempre uns pot-pourri nervoso e foxtrots saltitantes à jazz-band”. Com música ao vivo ou tocada pelos fonógrafos, e depois vitrolas, os gêneros e danças modernas tomaram conta dos clubes, bailes e salões de dança populares. O mesmo Sylvio Floreal se lembra que os salsifrés também "sofreram a invasão do modernismo porque possuem os seus jazz-bands que tocam foxtrot, tangos e shimmys". Quando os homens e mulheres, "desses que trocam a luz do dia pelas trevas", escreve Floreal, "partiam em peregrinação aos cabarets e às casas do vício", iam "estrangular as horas, à procura de esquecimento, numa taça de champagne ou na doidice embriagadora de uma jazz-band..." (Floreal, 2003, p. 32, 105, 156-157).

Ao se referir ao "teatro ligeiro" de São Paulo no período de 1915 a 1935, o cronista Jorge Americano informa que a revista Bataclan, com as "feéricas" francesas, de pouca roupa e muita plumagem, teria despertado "grande interesse de rapazes e senhores de óculos e até binóculos":

Josephine Baker se exibe com um corpo nu de macaca magra, enfeitado em certas partes, com algumas bananas. Diante do sucesso organiza-se uma "Companhia Negra” nacional de bailados, em cujos espetáculos se contorcem corpos nus com ritmos importados do sul dos Estados Unidos. (Americano, 1962, p. 233)

A febre do jazz também atingiu o meio negro de São Paulo na década de 1920. Reunidos em torno de clubes, centros cívicos, agremiações carnavalescas, jornais e salões de dança, sobretudo na região central da cidade, os chamados "homens de cor" realizavam reuniões sociais, festas e bailes que não estavam ligados às "sociedades-recreativas" dos segmentos elitizados, nem às dos imigrantes. Eram locais frequentados quase exclusivamente pela população negra, por isso ficaram conhecidos como "salões da raça". Seus bailes eram "abrilhantados" por orquestras, que se converteram em jazz-bands (Domingues, 2018; 
Moraes, 2000, p. 262). Consultando os jornais da “imprensa negra”, é possível identificar algumas delas: Jazz-Band American, do maestro João Amaral; Jazz-Band Ba-ta-clan, do maestro Júlio Mariano; Jazz Elite e Liberdade, dirigida por Benedicto Vianna; Jazz Flores, dirigida por José de Barros; Jazz Floresta e Jazz Progresso (Elite, 1924, p. 5; O Clarim d'Alvorada, 1925, p. 4; 1926, p. 6; p. 4; 1927, p. 6; Progresso, 1928, pp. 2, 5; 1929, p. 5).

No Rio de Janeiro, a projeção do jazz não se deu de maneira diferente. A capital da República, centro cultural, maior cidade e cartão de visita do país, desempenhava o papel de eixo de irradiação e caixa de ressonância das grandes transformações - desenvolvimento dos novos meios de comunicação, imprensa ilustrada, indústria fonográfica, o rádio, o cinema etc. - em marcha pelo mundo. O Rio ditava não só os sistemas de valores, o modo de vida, a sensibilidade, o estado de espírito relacionado à modernidade, mas também as novas modas (Sevcenko, 1998). E uma delas era justamente as danças e músicas modernas ligadas à tradição jazzística.

Lima Barreto, em crônica publicada na Gazeta de Notícias em fevereiro de 1922, conta que, em uma noite, quase em frente à sua casa na "Vila Quilombo" - alcunha que ele adotou para o bairro de Todos os Santos no subúrbio carioca -, houve um baile que atrapalhou bastante o seu sono. Das duas e meia até às quatro da madrugada, o escritor afro-brasileiro estivera acordado, ouvindo músicas "adoidadas e violentamente sincopadas, durante todo o tempo". Ficou intrigado. Pela manhã, ao tomar café em companhia dos familiares, perguntou à irmã se, nos "dias presentes", não se dançavam mais valsas, mazurcas, quadrilhas ou quadras, e o que ouviu de resposta foi:

- Qual! - disse-me ela. - Não se gosta mais disso... O que apreciam os dançarinos de hoje são músicas apolcadas, tocadas à la diable, que servem para dançar o tango, foxtrote, ragtime, e...

- Cake-walk? - perguntei.

- Ainda não se dança, ou já se dançou; mas agora, está aparecendo um tal de shimmy. (Barreto, 1956, p. 35) ${ }^{7}$

Diferentemente de Lima Barreto, o cronista Adolfo Morales de Los Rios percebeu bem a propagação arrebatadora das danças e músicas modernas no Rio de Janeiro, estimuladas pelos teatros, cinemas, sociedades recreativas e salões de dança e capitaneadas pela "gente moça": "Esta, por novidade ou esnobismo apreciava a Jazz-Band e sem esta não havia possibilidade de dançar o cake-walk" (Rios Filho, 1966, p. 79). Também as mulheres se apropriaram do 
novo gênero musical e suas danças (Carloni, 2019). Em 1923, a jazz-band, com diferentes sentidos, públicos e objetivos, já havia desencadeado uma explosão feérica no cenário artístico-musical da capital federal. "Em todos os cantos da cidade encontravam-se jazz-bands musicando algum evento" (Labres Filho, 2014, p. 75).

Com as empresas fonográficas investindo na música norte-americana, as jazz-bands pulularam de vez. Só na Casa Edison gravaram a Jazz Band do Batalhão Naval, a Orquestra Ideal Jazz Band, a American Jazz Band Sílvio de Souza e, sobretudo, a Jazz Band Sul Americana, de Romeu Silva (Severiano, 1997). No Rio de Janeiro, a onda das jazz-bands foi tão vulcânica que mesmo as orquestras de cordas, que tocavam geralmente nos cafés e nas confeitarias elegantes, adotaram o rótulo jazz-bands. Aliás, tais grupos fizeram parte da cultura associativa da cidade, transcendendo as fronteiras de classe, raça e bairro (Labres Filho, 2014). Quando Antonio Ferro - um jornalista, escritor e político português que firmou estreitos contatos com os modernistas brasileiros - realizou uma conferência no Teatro Lírico, no Rio, em julho de 1922, e a replicou em São Paulo, no Teatro Municipal, em setembro, e em mais dois lugares, ele enfatizou o significado da jazz-band:

O Jazz-Band, frenético, diabólico, destrambelhado e ardente, é a grande fornalha da nova humanidade. Por cada rufo sinistro de tambor, por cada furiosa arcada, há um corpo que se liberta, um corpo que fica reduzido a linhas, a linhas emaranhadas... O Jazz-Band é o triunfo da dissonância, é a loucura instituída em juízo universal [...] O Jazz-Band a encarnado e negro, a todas as cores, é o relógio que melhor dá as horas de hoje, as horas que passam a dançar, horas fox-trotadas, nervosas... No Jazz-Band, como num écram, cabem todas as imagens da vida moderna. (Ferro, 1922, p. 54-55)

Em outro momento da palestra, cujo texto foi publicado no opúsculo $A$ idade do jazz-band, Ferro volta a salientar que a "jazz-band é o dogma da nossa hora. Nós vivemos em jazz-band. Sofremos em jazz-band. Amamos em jazz-band" (Ferro, 1922, p. 66). São Paulo não ficou imune ao "dogma" que dava a tônica do mainstream. Surgiram ali a Jazz-band República - que era ligada ao cinema homônimo e alcançou grande fama no Planalto de Piratininga -, o Marion Jazz-band, do Theatro Sant'Anna, em 1921; Jazz-band Palácio, em 1922, do Palácio Theatro; Jazz-band Paulista, do Real Cabaret, em 1923; Jazz Band Manon, em 1924 (Moraes, 1995), entre muitos outros grupos.

Na cidade de Porto Alegre, despontou o Jazz Espia Só, em 1926, grupo 
liderado por Albino Rosa, um "crioulo" que trazia no "sangue o ritmo quente do sincopado e que viria mais tarde a se tornar popular". O grupo fez um sucesso quase instantâneo. Faltava agenda para atender à grande demanda dos clubes locais e mesmo do interior. Tocaram na Sociedade Satelista, que geralmente organizava seus saraus no Satélite Prontidão, ou na Sociedade Rui Barbosa. Também alegravam as noitadas do Clube Caixeral, do Clube do Comércio, da Sociedade Philosofia, usando para tanto os salões da Sociedade Germânia, que os cedia gentilmente. Aos sábados, feriados e em soirées aos domingos à tarde, o Jazz Espia Só era bastante requisitado, quando geralmente tocavam os ritmos da época (Vedana, 1987).

Quanto à cidade de Curitiba, o primeiro registro do jazz é de 1921; dois anos depois, Luiz Eulógio Zilli fundou a Curytiba Jazz Band, considerada a primeira da capital paranaense, onde as jazz-bands também atuaram com frequência nos salões de clubes, teatros, cinemas e sociedades artísticas. Mesmos os grupos que não possuíam a típica formação de uma jazz-band assim se intitulavam pelo modismo e pelo fato de que, para sobreviver no universo do entretenimento, os músicos circulavam por diferentes gêneros, estilos e performances (Giller, 2013).

Em 1926, foi criada a Jazz-Band Campinense Club, na cidade paraibana de Campina Grande; dois anos mais tarde, foi a vez da Jazz-Band Independência, em João Pessoa. No Recife, um grupo de jovens universitários, sob o comando do compositor Capiba, formou em 1931 a Jazz-Band Acadêmica de Pernambuco (Saldanha, 2008). Em suma, a coqueluche norte-americana se espraiou por todo o Brasil. É tanto que "penetrou até no interior do Nordeste, onde pequenos conjuntos de características fortemente rurais também adotaram o nome de jazz-band" (Cabral, 2007, p. 115).

Em novembro de 1919, a revista de variedades Leitura para todos publicou o artigo "Músicas e danças americanas", no qual se perguntava: "que cousa será o jazz?”, daí a própria magazine respondia:

Muitos jornais, confundindo a dança americana com a música, têm afirmado que o jazz é um novo bailado. Nada menos verdadeiro. O jazz é uma orquestra como outra qualquer, à qual alguns instrumentos antigos se foram juntar a outros modernos e que pode executar qualquer música. Não há dúvida que o ritmo é sempre apressado, quando se trata de ragtime ou de música sincopada, e nesse ritmo ligeiro pode ser executada qualquer música. Na jazz-band se pode tocar cançonetas napolitanas, valsas vienenses e até mesmo a nossa modinha chorosa. (Leitura para todos, 1919, p. 90) 
A revista Leitura para todos parece que tinha razão. Apesar do formato de orquestra importado, a jazz-band era um conjunto musical que reunia instrumentos "antigos" e "modernos" em torno de um repertório misto, o que passava por uma adaptação às coisas locais e nacionais - pelo menos é o que as pesquisas recentes têm apontado (Abreu, 2017; Giller, 2013; Labres Filho). As bandas não compunham e tocavam não apenas as músicas modernas estrangeiras, mas também o cancioneiro popular brasileiro (maxixes, sambas, marchas, choros, cateretês, cocos, emboladas sertanejas) (Lira, 1938) e outros estilos (polcas, valsas, tangos), retraduzidos de acordo com a tradição regional ou nacional. Ou seja, o repertório e os arranjos das jazz-bands eram ecléticos, polifônicos e informados pela lógica das trocas, empréstimos e fusões musicais. ${ }^{8}$

\section{CONSIDERAÇÕES FINAIS}

Não cabe polemizar se o jazz à brasileira era menos ou mais autêntico do que o norte-americano, pois o interesse deste trabalho foi apurar a inserção do jazz em nosso país, evidenciando que esse processo começou cedo, antes de 1920, porém é pouco conhecido na história social da música brasileira. Apesar da importância das novas pesquisas que têm se debruçado em torno da trajetória desse gênero em cidades específicas, falta ainda coligir muitos dados e informações para se montar um painel mais amplo e aprofundado da história do jazz e seu legado na cultura brasileira. Quanto a esse último aspecto, vale lembrar que o país já revelou grandes talentos e estéticas musicais que beberam no jazz e, ao mesmo tempo, atraiu importantes músicos norte-americanos especializados no gênero - como Booker Pittman, saxofonista que chegou a tocar com Louis Armstrong; Luís Cole, vocalista, sapateador e diretor de orquestra; Claude Austin, pianista, cantor e diretor de orquestra; Frankie Goodie "Big Boy", saxofonista - que aqui se radicaram (Pittman, 1984; Vidossich, 1966, p. 16).

O jazz foi expressão sonora dos novos tempos, de bonança econômica, de avanços científicos e tecnológicos, de inovações culturais e redefinições dos padrões de lazer, sociabilidade e congraçamento (Hobsbawm, 2009). Nascido em Nova Orleans, nos Estados Unidos, como música de negros e reconhecido a posteriori como espécie de símbolo da identidade nacional, o novo estilo viajou por cidades como Kansas, Nova York, Chicago e adquiriu contornos transnacionais à medida que se expandiu pelo Mundo Atlântico, tendo sido apropriado no show business de Paris, Berlim, Madri, Buenos Aires, São Paulo e Rio de Janeiro como um emblema da modernidade, o que impulsionou o 
engendramento de um novo paradigma cultural para todos que se divertiam, seja ouvindo, dançando ou tocando aquela contagiante música híbrida, afrodiaspórica. Alvo do fascínio da indústria fonográfica, do cinema, do teatro, dos jornais e das revistas, o jazz circulou nas redes de conexões culturais globais, embora tivesse assumido significados, roupagens e cores locais.

Em outros termos, o jazz tornou-se o vocabulário musical dos diálogos transnacionais associados ao cosmopolitismo e às modernidades do pós-Guerra, tendo sido interpretado e reinterpretado nos diversos contextos em que se fez presente. Com a voga das danças de salão, do teatro de revista, do rádio, do fonógrafo e do cinema, essa forma musical mutante, para não dizer ressignificada, ocupou um lugar de destaque na indústria do lazer, tornando-se um bem cultural de grande impacto e difusão no Brasil dos "anos vinte". ${ }^{9}$ O que as pessoas esperavam nas festas e bailes sob os acordes de uma jazz-band eram o deleite, as mais delirantes fantasias e a certeza de que o prazer existia e era possível desejá-lo. Ter aquele campo tímbrico-instrumental vinculado às principais formas de entretenimento do período contribuiu deveras para o seu sucesso visceral. Sons, imagens, sensibilidades e movimentos sincopados serviam para definir expectativas e experiências liberalizantes e excitantes da vida moderna.

\section{REFERÊNCIAS}

ABREU, Martha. Da senzala ao palco: canções escravas e racismo nas Américas, 18701930. Campinas: Editora Unicamp, 2017.

ALBERTO, Paulina. Terms of inclusion: black intellectuals in twentieth-century Brazil. Chapel Hill: The University of North Carolina Press, 2011.

A LIBERDADE, São Paulo, 9 nov. 1919.

ALMIRANTE. No tempo de Noel Rosa: a verdade definitiva sobre Noel e a música popular. São Paulo: Francisco Alves, 1963.

AMERICANO, Jorge. São Paulo nesse tempo (1915-1935). São Paulo: Edições Melhoramentos, 1962.

AMERICANO, Jorge. São Paulo naquele tempo (1895-1915). 2. ed. São Paulo: Carrenho Editorial, 2004.

A NOITE, Rio de Janeiro, 28 dez. 1916.

A NOITE, Rio de Janeiro, 8 jul. 1917.

A NOITE, Rio de Janeiro, 13 dez. 1915.

ARAÚJO, Vicente de Paula. Salóes, circos e cinemas de São Paulo. São Paulo: Perspectiva, 1981. 
BAKHTIN, Mikhail. Gêneros do discurso. Tradução: Paulo Bezerra. São Paulo: Editora 34, 2016.

BARRETO, Lima. Marginália: artigos e crônicas. São Paulo: Brasiliense, 1956.

BARSALINI, Leandro. Sobre baterias e tamborins: as jazz-bands e a batucada de samba. Revista do Instituto de Estudos Brasileiros, São Paulo, n. 70, p. 59-77, 2018.

BASTIDE, Roger. A imprensa negra do estado de São Paulo. Sociologia: Boletim da Faculdade de Filosofia, Ciência e Letras da Universidade de São Paulo, São Paulo, v. 121, n. 2, p. 50-78, 1951.

BASTOS, Rafael José de Menezes. Les Batutas, 1922: uma antropologia da noite parisiense. Revista Brasileira de Ciências Sociais, São Paulo, v. 20, n. 58, p. 177-213, 2005.

BILLARD, François. No mundo do jazz. São Paulo: Companhia das Letras, 2001.

BLAKE, Jody. Le tumulte noir: modernist art and popular entertainment in jazz age Paris, 1900-1930. University Park: Pennsylvania State University Press, 1999.

BORGE, Jason. Tropical riffs: Latin America and the politics of jazz. Durham: Duke University Press, 2018.

CABRAL, Sérgio. Pixinguinha: vida e obra. 4. ed. Rio de Janeiro: Funarte, 2007.

CARLONI, Karla. "Requebrando os quadris": jazz e transgressão feminina nas revistas ilustradas cariocas da década de 1920. Locus, Juiz de Fora, v. 25, n. 2, p. 79-99, 2019. CORREIO DA MANHÃ, Rio de Janeiro, 2 ago. 1916.

CORREIO DA MANHÃ, Rio de Janeiro, 7 dez. 1916.

Da platéa. A Noite, Rio de Janeiro, 6 jul. 1919.

DOMINGUES, Petrônio. Os jornais dos filhos e netos de escravos (1889-1930). In: DOMINGUES, Petrônio. A nova abolição. São Paulo: Selo Negro, 2008. p. 19-58. DOMINGUES, Petrônio. Nos acordes da raça: a era do jazz no meio afro-brasileiro. Tempo e Argumento, Florianópolis, v. 10, n. 25, p. 66-98, 2018.

ELITE, São Paulo, 2 mar. 1924.

FERRARA, Miriam Nicolau. A imprensa negra paulista (1915-1963). São Paulo: FFLCH/USP (Antropologia 13), 1986.

FERRO, Antonio. A idade do jazz-band. São Paulo: Off. Graph. Monteiro Lobato \& CO., 1922.

FITZGERALD, Scott F. Seis contos da era do jazz. 2. ed. Rio de Janeiro: Civilização Brasileira, 1965.

FLOREAL, Sylvio. Ronda da meia-noite: vícios, misérias e esplendores da cidade de São Paulo. São Paulo: Paz e Terra, 2003.

FON-FON, Rio de Janeiro, 8 dez. 1917.

FON-FON, Rio de Janeiro, 15 dez. 1917.

GAY, Peter. Modernismo: o fascínio da heresia - de Baudelaire a Beckett e mais um pouco. São Paulo: Companhia das Letras, 2009.

GAZETA DE NOTÍCIAS, Rio de Janeiro, 17 ago. 1916. 
GAZETA DE NOTÍCIAS, Rio de Janeiro, 7 fev. 1922.

GILLER, Marilia. O Jazz no Paraná entre 1920 a 1940: um estudo da obra O sabiá, fox trot shimmy de José da Cruz. Dissertação (Mestrado em Música) - Faculdade de Artes, Universidade Federal do Paraná, Curitiba, 2013.

GILROY, Paul. O Atlântico negro: modernidade e dupla consciência. São Paulo: Editora 34, 2001.

GIOIA, Ted. The history of jazz. New York: Oxford University Press, 1997.

GROSSMAN, James R. A chance to make good: african-americans, 1900-1929. New York: Oxford University Press, 1997.

GUINLE, Jorge. Jazz Panorama. Rio de Janeiro: Agir, 1953.

HALL, Stuart. Da diáspora: identidades e mediações culturais. Belo Horizonte: Editora UFMG, 2003, Brasília: Representação da Unesco no Brasil.

HELBLING, Mark. The Harlem Renaissance: the one and the many. Westport: Greenwood Press, 1999.

HOBSBAWM, Eric. História social do jazz. Rio de Janeiro: Paz e Terra, 2009.

HOBSBAWM, Eric. Era dos extremos: o breve século XX (1914-1991). São Paulo: Companhia das Letras, 1995.

IKEDA, Alberto T. Apontamentos históricos sobre o jazz no Brasil: primeiros momentos. Comunicação e Artes (USP), São Paulo, v. 13, p. 111-124, 1984.

IKEDA, Alberto T. Música na cidade em tempo de transformação: São Paulo, 19001930. Dissertação (Mestrado em Artes) - Escola de Comunicações e Artes, Universidade de São Paulo, São Paulo, 1988.

Ilusão. O Alfinete, São Paulo, 9 mar. 1919.

JORNAL DO BRASIL, Rio de Janeiro, 24 abr. 1917.

LABRES FILHO, Jair Paulo. Que jazz é esse? As jazz-bands no Rio de Janeiro da década de 1920. Dissertação (Mestrado em História) - Instituto de História, Universidade Federal Fluminense, Niterói, 2014.

LEITURA PARA TODOS, Rio de Janeiro, 20 nov. 1919.

LIRA, Mariza. Brasil sonoro: gênero e compositores populares. Rio de Janeiro: A Noite, 1938.

MARTINS, Luiza Mara Braga. Os Oito Batutas: história e música brasileira nos anos 1920. Rio de Janeiro: Editora UFRJ, 2014.

MORAES, José Geraldo Vinci de. As sonoridades paulistanas: a música popular na cidade de São Paulo - final do século XIX ao início do século XX. Rio de Janeiro: Funarte, 1995.

MORAES, José Geraldo Vinci de. Metrópole em sinfonia: história, cultura e música popular na São Paulo dos anos 30. São Paulo: Estação Liberdade, 2000.

NETO, Lira. Uma história do samba: as origens. São Paulo: Companhia das Letras, 2017.

O CLARIM D’ALVORADA, São Paulo, 25 jan. 1925. 
O CLARIM D’ALVORADA, São Paulo, 24 jan. 1926.

O CLARIM D'ALVORADA, São Paulo, 24 jun. 1926.

O CLARIM D’ALVORADA, São Paulo, 15 jan. 1927.

O CLARIM D'ALVORADA, São Paulo, 21 out. 1928.

O ESTADO DE SÃO PAULO, São Paulo, 19 dez. 1917.

O ESTADO DE SÃO PAULO, São Paulo, 16 jan. 1920.

O FLUMINENSE, Niterói, 26 abr. 1904.

O MALHO, Rio de Janeiro, 9 jul. 1904.

O PAIZ, Rio de Janeiro, 15 jun. 1903.

O PAIZ, Rio de Janeiro, 10 jun. 1906.

O PAIZ, Rio de Janeiro, 7 fev. 1907.

O PAIZ, Rio de Janeiro, 26 fev. 1916.

O PAIZ, Rio de Janeiro, 26 maio 1916.

O RIO-NÚ, Rio de Janeiro, 27 maio 1903.

PENTEADO, Jacob. Memórias de um postalista. São Paulo: Editora Martins, 1963.

PITTMAN, Ophelia. Por você, por mim, por nós. Rio de Janeiro: Record, 1984.

PORTO, Sérgio. Pequena história do jazz. Rio de Janeiro: Serviço de Documentação do Ministério da Educação e Saúde, 1953.

PROGRESSO, São Paulo, 23 jun. 1928.

PROGRESSO, São Paulo, 15 nov. 1928.

PROGRESSO, São Paulo, 23 jun. 1929.

REVISTA DA SEMANA, Rio de Janeiro, 5 jul. 1903.

REVISTA DA SEMANA, Rio de Janeiro, 8 ago. 1914.

RIO, João do. A alma encantadora das ruas. São Paulo: Companhia das Letras, 2008.

RIOS FILHO, Adolfo Morales de los. O Rio de Janeiro da Primeira República (18891930). Revista do Instituto Histórico e Geográfico Brasileiro. Rio de Janeiro, v. 273, p. 3-116, 1966.

ROSE, Phyllis. A Cleópatra do jazz: Josephine Baker e seu tempo. Rio de Janeiro: Rocco, 1990.

SALDANHA, Leonardo Vilaça. Frevendo no Recife: a música popular urbana do Recife e sua consolidação através do rádio. Tese (Doutorado em Música) - Instituto de Artes, Universidade Estadual de Campinas, Campinas, 2008.

SEIGEL, Micol. Uneven encounters: making race and nation in Brazil and The United States. Durham, NC: Duke University Press, 2009.

SEVCENKO, Nicolau. Orfeu extático na metrópole: São Paulo sociedade e cultura nos frementes anos 20. São Paulo: Companhia das Letras, 1992.

SEVCENKO, Nicolau. A capital irradiante: técnica, ritmos e ritos do Rio. In: SEVCENKO, Nicolau (org.). História da vida privada no Brasil: República. São Paulo: Companhia das Letras, 1998, v. 3, p. 513-619. 
SEVERIANO, Jairo; MELLO, Zuza Homem de. A canção no tempo: 85 anos de músicas brasileiras. São Paulo: Editora 34, 1997, v. 1, 1901-1957.

SHAW, Lisa. Tropical travels: brazilian popular performance, transnacional encounter, and the construction of race. Austin: University of Texas Press, 2018.

STEARNS, Marshall. A história do jazz. São Paulo: Livraria Martins, 1956.

TINHORÃO, José Ramos. História social da música popular brasileira. Rio de Janeiro: Editora 34, 1998.

ULANOV, Barry. A história do jazz. Rio de Janeiro: Civilização Brasileira, 1957.

Vagando. A Liberdade, São Paulo, 23 nov. 1919.

VASCONCELLOS, Ary. Panorama da música popular brasileira na Belle Époque. Rio de Janeiro: Martins: Livraria Sant'Anna, 1977.

VEDANA, Hardy. Jazz em Porto Alegre. Porto Alegre: L\&PM, 1987.

VIDOSSICH, Edoardo. Jazz na garoa. São Paulo: Edição da Associação dos Amadores de Jazz Tradicional, 1966.

WILSON, Edmund. Os anos vinte: extraído dos cadernos e diários. São Paulo: Companhia das Letras, 1987.

\section{Notas}

${ }^{1}$ Sérgio Porto, mais conhecido pelo pseudônimo Stanislaw Ponte Preta, publicou um livro sobre a história do jazz, o qual definiu como sendo o primeiro que se fez no Brasil. Nesse livro, ele endossa a versão de que a palavra jazz nasceu mais ou menos em 1915, por ocasião dos concertos de uma orquestra de Tom Brown no Lamb’s Café, em Chicago: "Os músicos não eram sindicalizados e as uniões profissionais do lugar procuraram intimidar o estabelecimento, passeando, diante de sua entrada, um grupo de homens-sandwich com cartazes em que se lia que a música do Lamb's era uma jass-music. Isso significava que a orquestra de Tom Brown sairia do quarteirão reservado, pois a expressão jass, ou jazz, era a mais vil palavra de gíria que designava os encontros carnais nos bordéis. O proprietário do Café não deixou passar a ocasião que se lhe oferecia e usou o insulto para fins publicitários. Anunciou a Brown's Dixieland Jass Band. E foi assim que um pouco mais tarde se adotou a palavra jazz" (Porto, 1953, p. 22-23).

${ }^{2}$ GAZETA DE NOTÍCIAS, Rio de Janeiro, 26 dez. 1906. Essa crônica ("Como se ouve a missa do galo") de João do Rio foi republicada no seu livro A alma encantadora das ruas (Rio, 2008, p. 132-139). Para uma discussão sobre os sentidos e significados do cake-walk, nos Estados Unidos e no Rio de Janeiro desse período, ver Abreu (2017), notadamente os capítulos Um gênero das senzalas no mundo moderno e Das plantations às partituras nos Estados Unidos.

${ }^{3}$ Ao que tudo indica, as sonoridades do jazz já eram praticadas antes de 1917, mas foi por volta desse ano que surgiu um consenso aceito por muitas pessoas de que aquelas sonoridades podiam ser denotadas pelo vocábulo "jazz". Isso tem a ver com aquilo que Mikhail 
Bakhtin (2016) chamou de estabilidade dos gêneros do discurso. É impossível saber a origem deles, mas é possível estabelecer quando as pessoas aceitam que um termo designe um conjunto de práticas.

${ }^{4}$ Alberto Ikeda (1984, p. 117) sugere que o ragtime era conhecido no Brasil antes de 1917; "talvez através de partituras musicais, mas mais provavelmente pela divulgação de alguma companhia teatral ou de circo, ou até mesmo através dos rolos de música (discos)”.

${ }^{5}$ Convencionou-se designar de imprensa negra o conjunto de jornais e revistas feitos por afro-brasileiros e dedicados a tratar de suas questões. A respeito desses periódicos, ver Bastide (1951), Ferrara (1986), Domingues (2008, p. 19-58), Alberto (2011).

${ }^{6}$ Eis o que Lira Neto escreve textualmente: sob a liderança de Pixinguinha, "os Batutas, que levaram à Europa um repertório de maxixes, choros, lundus e sambas, tiveram a oportunidade de entrar em contato com um mundo musical para eles absolutamente inédito. $\mathrm{Na}$ convivência com instrumentistas de jazz, a maioria oriundos de Nova Orleans, iriam conhecer e se apropriar de outras linguagens, bossas e atitudes, incorporando-as ao próprio modo de tocar" (Lira Neto, 2017, p. 135).

${ }^{7}$ GAZETA DE NOTÍCIAS, Rio de Janeiro, 7 fev. 1922. Essa crônica ("Bailes e divertimentos suburbanos") de Lima Barreto foi republicada no seu livro Marginália: artigos e crônicas (Barreto, 1956).

${ }^{8}$ Conforme nota Leandro Barsalini, "não se deve considerar as jazz-bands brasileiras necessariamente como bandas cujo repertório era estritamente executado na linguagem jazzística; e sim como sinônimo de grupo que produzia um som dançante e moderno, conectado às novidades sonoras e visuais vindas do exterior, refletidas em seus trajes, sua postura e em sua instrumentação" (Barsalini, 2018, p. 66).

${ }^{9}$ Para um livro recente que examina como as trocas artístico-culturais (de música e dança a teatro e cinema) na arena transatlântica e interamericana desse período redefiniram a identidade brasileira, especialmente a percepção de "raça", ver Shaw (2018).

Artigo recebido em 19 de fevereiro de 2020.

Aprovado em 30 de julho de 2020. 